\title{
Rhodamine backfilling and confocal microscopy as a tool for the unambiguous identification of neuronal cell types: A study of the neurones of the rat cochlear nucleus
}

\author{
Krisztina Pocsai, Balázs Pál, Pál Pap, Gábor Bakondi, Lívia Kosztka, \\ Zoltán Rusznák, Géza Szúcs* \\ Department of Physiology, Medical and Health Science Centre, University of Debrecen, PO Box 22, H-4012 Debrecen, Hungary
}

Received 26 July 2006; received in revised form 17 October 2006; accepted 19 November 2006

\section{Introduction}

The mammalian cochlear nucleus $(\mathrm{CN})$ is the structure where the incoming primary acoustic information is passed onto several secondary ascending pathways formed by the axons of various projection neurones. Morphologically, the $\mathrm{CN}$ has a highly organised and complex cytoarchitecture $[6,7,10,16,21-23,33,39,42]$, in which the projection neurones are located in distinct parts of the nucleus. Generally, the anterior part of the ventral $\mathrm{CN}(\mathrm{aVCN})$ contains globular and spherical bushy cells as well as stellate neurones; octopus cells are situated

\footnotetext{
* Corresponding author. Tel.: +36 52416 634; fax: +36 52432289.

E-mail address: szg@phys.dote.hu (G. Szűcs).
}

in the posterior part of the ventral $\mathrm{CN}(\mathrm{pVCN})$; giant cells are scattered in both the VCN and the dorsal CN (DCN); whereas pyramidal neurones and Purkinje-like cells (PLCs) are found in the DCN only. The activity of neuronal networks consisting of the projection cells and the numerous interneurones ensures that the incoming acoustic information is not merely distributed, but processed in the $\mathrm{CN}$. Consequently, the projection neurones actively contribute to the decoding of the acoustic information. The axons of these cells form the efferent pathways targeting various structures in the brain stem, and carry information about different aspects of the sound stimuli (amplitude, onset, duration, etc.).

In a study aiming at the description and understanding of the activity of such a complex neuronal structure as the $\mathrm{CN}$, it is imperative to clearly define the functional contribution of 
the individual cell types. Although in some cases information about the presence and localisation of different membrane and cytoplasmic proteins (i.e. receptors, ion channel subunits, transporters, ion-binding elements, members of transmitter-synthesis pathways, etc.) may help in comprehending the functional significance of the individual classes of neurones, functional measurements are indispensable. One of the possible methods to gain information about the function of neurones is the application of microelectrode techniques in a thin slice preparation. In this case, however, the initial cell identification is mostly restricted to the visual information provided by the differentialinterference contrast (DIC) optics. As the DIC image alone rarely provides enough data for unambiguous cell classification, other methods are also routinely applied aiming at the better visualisation of the investigated neurones. In a number of cases a fluorescent dye (e.g. Lucifer Yellow) is added to the pipette solution (see e.g. [8,14,24,26,29]), and cell classification is achieved after completing the functional experiments, when the dye diffused into the cells. In these instances numerous aspects of the morphology may be taken into account for determining the cell type, including the shape and localisation of the cell body as well as the arrangement of the visible dendritic arborisation. However, often even these characteristics are not sufficient for unambiguous cell identification-especially, when the plane of the sectioning was not optimal, when the dye did not fill the examined neurones properly or when one or more processes of the investigated neurones were lost during the preparation of the slices. Occasionally, similar problems may also be faced after performing immunohistochemical labelling of the $\mathrm{CN}$ (see e.g. $[19,30,46])$. The difficulties of cell classification may eventually result in misidentifications, making the interpretation and potential use of the experimental data dubious.

It is essential, therefore, that a firm basis is established that can be effectively employed for the precise classification of the $\mathrm{CN}$ neurones, even in combination with functional measurements. Although in the past decades several visualisation techniques were tried to determine the structures of these cells, including impregnation methods (see e.g. $[5,6,16,21,45])$ and various filling techniques (see e.g. [8,14,26,27,33,37]), most of them have certain disadvantages (i.e. they do not provide much information on the functions, or they are applicable on a limited number of cells only).

The primary aim of the present confocal analysis was, therefore, to establish morphological criteria which may help in the precise identification of the principal neurones (bushy, pyramidal, giant, octopus cells and PLCs) of the rat $\mathrm{CN}$, which may help unambiguous cell classification after completing functional measurements. The present study took advantage of the unique possibility provided by confocal microscopy, allowing the sectioning and reconstruction of the three-dimensional morphology of the individual cell types; thus it became possible to reproduce images which are encountered when the neurones are viewed from angles providing unusual morphological appearances. Moreover, it was also specifically investigated to what extent the individual cell types can resemble each other's morphology; and if so, what may be the most likely identification errors.

\section{Materials and methods}

\subsection{Animal care}

The experiments were conducted on 1-month-old Wistar rats (from both sexes) following a protocol that was authorised by the Ethical Committee of the University of Debrecen and was in accordance with the appropriate international and Hungarian laws. The animals were bred in the departmental animal house and they lived in an environment with natural day-night cycles (window light), where food and water were available ad libitum. The animals were subjected to the smallest possible pain and discomfort during the experimental procedures.

\subsection{Retrograde labelling}

All steps of the preparation [30] were performed in ice-cold (approx. $-2{ }^{\circ} \mathrm{C}$ ) low- $\mathrm{Na}^{+}$artificial cerebrospinal fluid (aCSF) that was made of (in $\mathrm{mM}$ ): sucrose, 250; KCl, 2.5; glucose, $10 ; \mathrm{NaHCO}_{3}, 26 ; \mathrm{NaH}_{2} \mathrm{PO}_{4}, 1.25 ; \mathrm{CaCl}_{2}, 2 ; \mathrm{MgCl}_{2}, 1$; myo-inositol, 3; ascorbic acid, 0.5; Na-pyruvate, 2 (pH: 7.2; tonicity: 320 mOsm; all chemicals were purchased from Sigma-Aldrich, St. Louis, MO, USA unless stated otherwise).

After the decapitation of the animal, the brain was removed and placed into a Sylgard-coated Petri-dish. A total of 27 animals were used for retrograde filling and usable preparations were obtained in 24 cases. When the labelling proved to be unsuccessful, the cells were either not labelled at all, or their morphology could not be assessed owing to very high background fluorescence. The most likely explanations of the inadequate labelling were inappropriate positioning of the cuts and/or relatively low concentration of rhodamine, and/or photobleaching of the dye.

Retrograde labelling was performed by using tetramethylrhodamine-dextran (lysine fixable, molecular weight $=3000$; Molecular Probes Inc., Oregon, USA; referred to as rhodamine throughout). The excitation/emission maxima of this compound were 555 and $580 \mathrm{~nm}$, respectively.

The incisions (described below) necessary for the application of the retrograde tracer were performed in a Sylgard-coated Petri dish filled with low- $\mathrm{Na}^{+}$ aCSF. The tissue was continuously oxygenated with the mixture of $95 \% \mathrm{O}_{2}$ and $5 \% \mathrm{CO}_{2}$. Prior to the application of the dye, the cut surface of the brain was dried with a small piece of filter paper. The labelling was achieved by either placing a few rhodamine crystals into the incisions or injecting concentrated rhodamine solution $(1 \mathrm{mg} / 100 \mu \mathrm{l}$ phosphate buffer [PB]) into the appropriate part of the brain tissue. All steps were performed in a dark room to avoid photobleaching.

The exact locations of the incisions as well as the rhodamine administration methods were determined according to the types of targeted neurones [37]. Fig. 1 demonstrates the exact positions of the lesions; the cuts were performed bilaterally in 12 animals.

Labelling of the bushy neurones (no distinction was made between the spherical and globular ones in this study) was performed by severing the trapezoid body at the ventral end of the VCN, as close to the nucleus as possible (Fig. 1A; $n=4)$. The length of the incision was $3-5 \mathrm{~mm}$, with a depth of $1.5-2.5 \mathrm{~mm}$.

When giant and pyramidal cells of the DCN were targeted (Fig. 1B; $n=5$ ), the cerebellum was removed, and the axons of giant and pyramidal cells were cut by severing the dorsal acoustic stria. The incision was made in the parasagittal plane, approximately $2 \mathrm{~mm}$ medially from the medial edge of the DCN. The length and depth of the incision were both $1 \mathrm{~mm}$; when the incision was deeper or it was closer to the nucleus, octopus neurones became also labelled as in these cases the intermediate acoustic stria also became affected.

Isolated incision of the intermediate acoustic stria, where axons of the octopus neurones leave the $\mathrm{CN}$, was very difficult to perform without injuring the axons of the giant and pyramidal cells, thus octopus neurones were labelled by mechanically injecting concentrated rhodamine solution into the intermediate acoustic stria $(n=5$; Fig. $1 \mathrm{C})$. The injection was performed $0.5 \mathrm{~mm}$ medially from the medial edge of the DCN at a depth of $1.6-1.8 \mathrm{~mm}$ in a direction precisely perpendicular to the surface of the brain stem. The pressure applied during the injection was kept as low as possible; higher injection pressures resulted in diffusion of the dye towards neighbouring structures causing labelling of pyramidal and giant cells as well.

Retrograde labelling of PLCs was performed by cutting the inferior, medial and superior cerebellar peduncles (without removing the cerebellum) and applying the tracer at the sites of these lesions (Fig. 1D; $n=5$ ). 

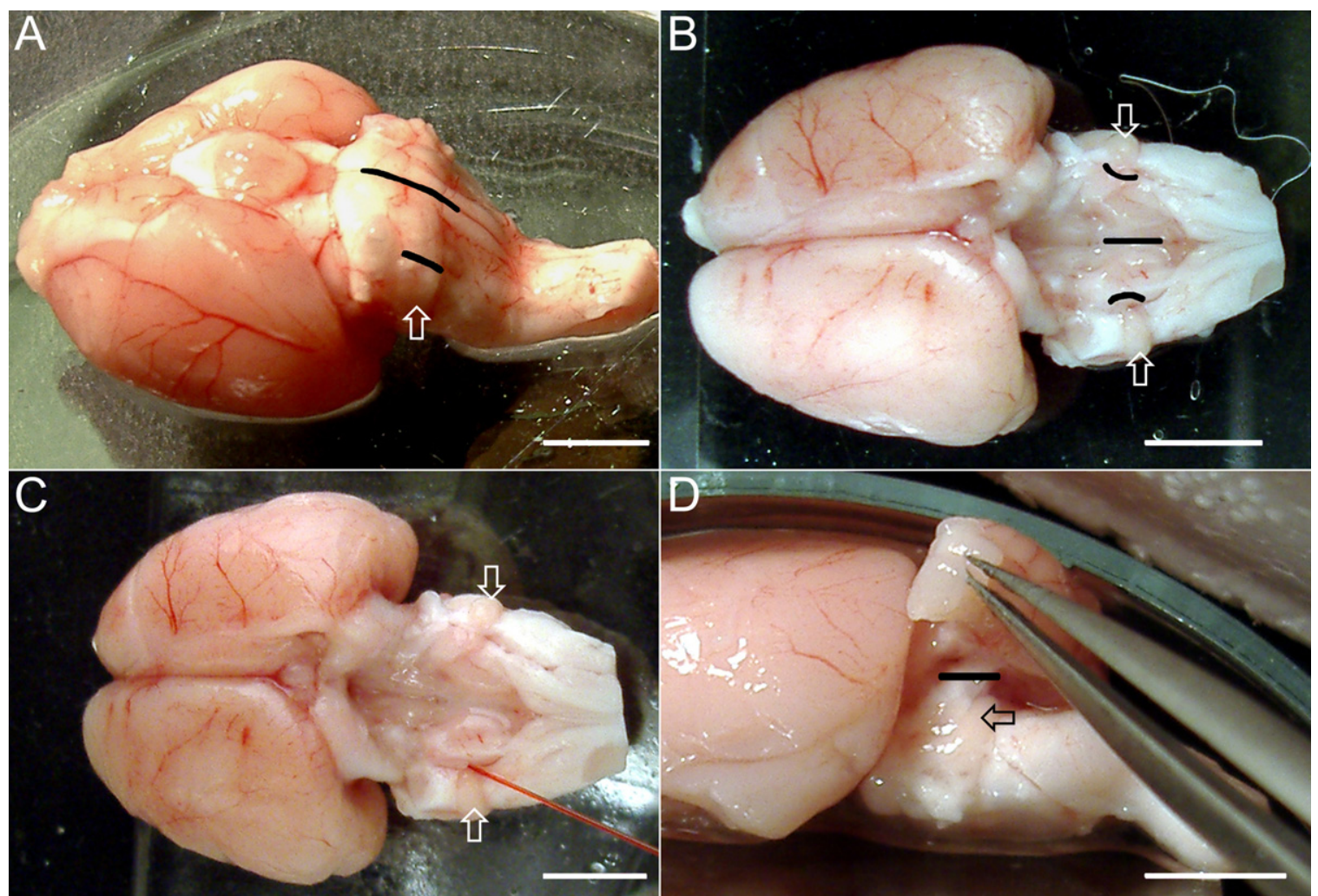

Fig. 1. Locations of the lesions made for labelling the different $\mathrm{CN}$ projection neurones. Arrows indicate the $\mathrm{CN}$, lines show the locations of the cuts and rhodamine applications. (A) Shorter line indicates the location of rhodamine application for labelling bushy cells. The line in the midst represents the case when the cut targeted all axons projecting to contralateral structures. (B) Cuts severing the dorsal acoustic stria for labelling pyramidal and giant cells. The line in the midst has the same meaning as in (A). (C) Needle is inserted into the intermediate acoustic stria for labelling octopus neurones (the cerebellum was removed). (D) Labelling the PLCs from lesions made at the cerebellar peduncles. Calibrations: $1 \mathrm{~cm}$ in each case.

Occasionally, labelling of all projection neurones targeting contralateral structures was desired, which was achieved by applying a 5-8 $\mathrm{mm}$ deep ventral incision of the brain stem exactly at the midline, at the level of the trapezoid body (Fig. 1A and B; $n=5$ )

\subsection{Preparations of the tissue sections after the retrograde labelling}

Completion of the cuts and application of the fluorescent dye were followed by the incubation of the brain in normal aCSF (composition similar to that of the low- $\mathrm{Na}^{+}$aCSF except that sucrose was substituted with $125 \mathrm{mM} \mathrm{NaCl}$ ), which was continuously oxygenated. The incubation $(8-12 \mathrm{~h})$ was performed in total darkness. At the end of the procedure, the preparation was transferred into $4 \%$ paraformaldehyde solution and stored at $4{ }^{\circ} \mathrm{C}$ for $12 \mathrm{~h}$. Following three rinses in $\mathrm{PB}(\mathrm{pH}$ 7.4) 50-60 $\mu \mathrm{m}$ thick sagittal slices were cut from the $\mathrm{CN}$ ipsilateral to the incisions by using vibratome (Campden Instruments, Loughborough, UK; Microm International GmbH, Walldorf, Germany). Sections were washed in Tris-buffered saline ( $\mathrm{pH} 7.4$; TBS; $3 \times 10 \mathrm{~min})$ and mounted in Vectashield mounting medium containing DAPI (Vector Laboratories Inc., Burlingame, CA, USA).

\subsection{Immunolabelling in free-floating slices}

Calbindin-specific immunolabelling of the PLCs was conducted in freefloating slices. In these cases the isolated brain stems were fixed in $4 \%$ paraformaldehyde solution $\left(4^{\circ} \mathrm{C}, 4 \mathrm{~h}\right)$, rinsed three times in $0.1 \mathrm{M} \mathrm{PB}$ for $10 \mathrm{~min}$, and 50-60 $\mu \mathrm{m}$ thick sagittal slices were cut. The tissue sections were washed in PB for $10 \mathrm{~min}$ then rinsed with TBS $(3 \times 10 \mathrm{~min})$. Blocking was performed with $10 \%$ normal rabbit serum dissolved in TBS containing $0.1 \%$ Triton X-100 for $1 \mathrm{~h}$ at room temperature, followed by the incubation with the primary anti- body (polyclonal, goat anti-calbindin IgG [1:500; Santa Cruz Biotechnology Inc., Santa Cruz, CA, USA]) overnight (room temperature). On the following day, the slices were rinsed in TBS $(3 \times 10 \mathrm{~min})$ and incubated with Texas red- or FITC-conjugated rabbit anti-goat IgG (Vector Laboratories Inc.) for $3 \mathrm{~h}$ at room temperature, followed by further washes in TBS $(3 \times 10 \mathrm{~min})$. At the end of the protocol, the slices were mounted using Vectashield mounting medium. Altogether six animals were used for calbindin-specific immunolabelling.

\subsection{Microscopy}

Both the retrograde labelling and the immunoreactions were visualised by either a fluorescence microscope (Eclipse 600W; Nikon, Tokyo, Japan; in this case the images were acquired by using the Spot RT v3.5 software) or a laser scanning confocal microscope (Zeiss LSM 510 microscope; Oberkochen, Germany). In the latter case 20-80 "Z-stack" images (optical sections) were obtained from the cells of interest by using a $40 \times$ oil-immersion objective. The thickness of the individual optical sections varied between 0.6 and $1.0 \mu \mathrm{m}$. The reconstruction of the composite images (the summation of the individual Z-stack images providing the three-dimensional appearance of the cells) was performed by using the Zeiss LSM Image Browser software. The same program was used to rotate the composite images to check the morphological appearances of the investigated cells as they were viewed from various directions, mimicking the situation when the sectioning plane of the slices is altered. The final forms of the illustrations were created by using Adobe Photoshop 7.0 .

\subsection{Quantitative analysis}

For the quantitative analysis, each investigated cell had to fulfil three criteria: the cell type had to be determined without doubt; the cell body and proximal

Please cite this article in press as: K. Pocsai et al., Rhodamine backfilling and confocal microscopy as a tool for the unambiguous identification of neuronal cell types: A study of the neurones of the rat cochlear nucleus, Brain Res. Bull. (2006), doi:10.1016/j.brainresbull.2006.11.009 


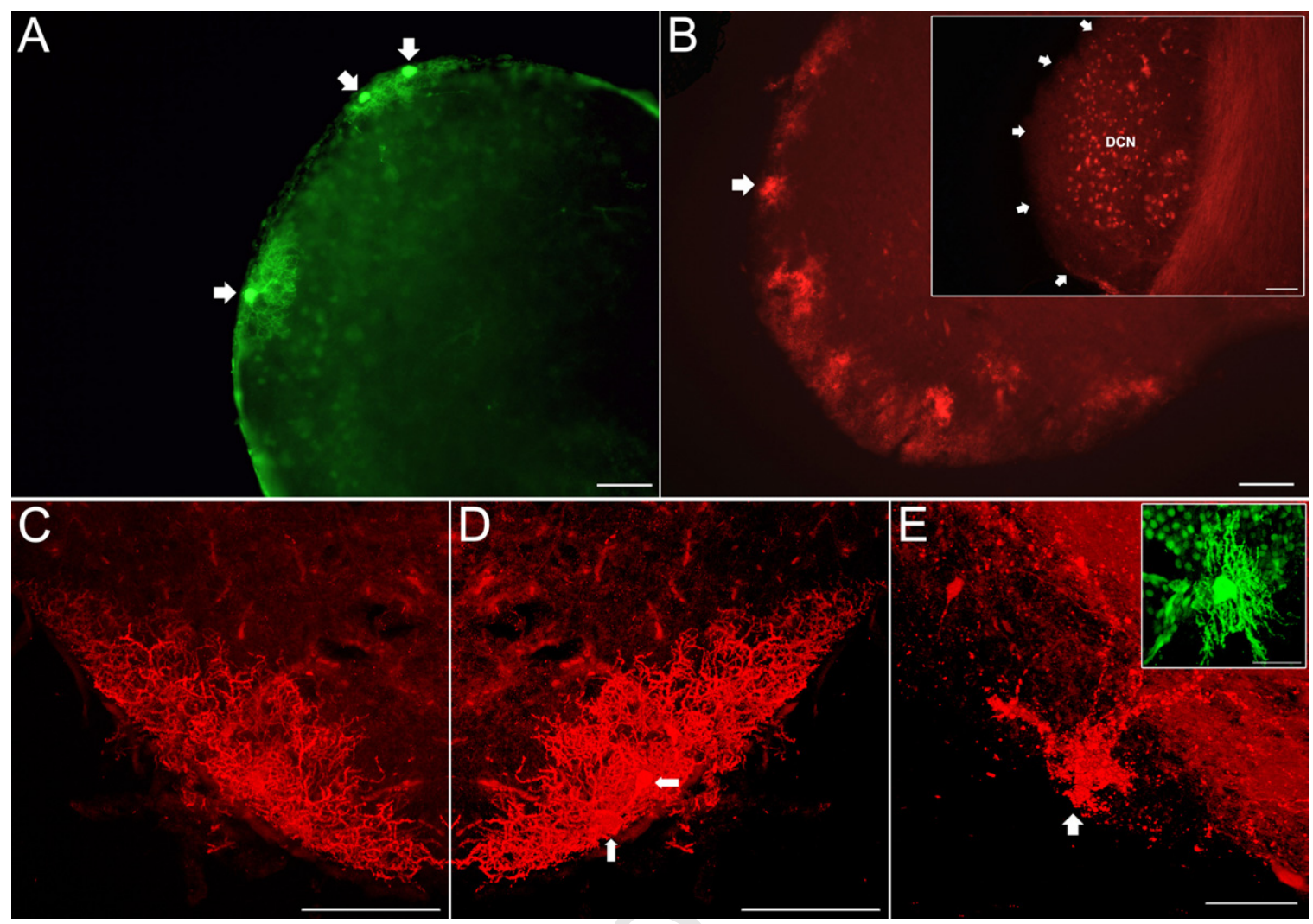

Fig. 2. Morphology and retrograde labelling of Purkinje-like cells (PLCs) in the DCN. (A) Low magnification view of three calbindin-labelled PLCs. (B) Appearance of rhodamine-filled structures when the lesion was performed at the cerebellar peduncles (main image, arrow). Inset shows the result of the labelling when the lesion was performed at the mid-line, arrows indicate the outline of the DCN. (C and D) Calbindin-positivity of two PLCs. (D) was obtained by $180^{\circ}$ rotation of (C), in this case the cell bodies became visible (arrows). (E) High magnification, composite image of a rhodamine filled PLC (main image). Arrow indicates the most likely position of the cell body. Inset shows the image of a single calbindin-positive PLC. Calibrations: $100 \mu \mathrm{m}$ (A, B: main image and inset, C, D); $50 \mu \mathrm{m}$ (E: main image and inset).

segments of the processes had to be free of any apparent damage, and the neurone had to be adequately filled with rhodamine. Some of the measurements performed on the PLCs were conducted after their calbindin-specific labelling. Both the number of processes and the diameter of the cell bodies were either determined in the composite image or by using the individual optical sections. In the cases of elongated, triangular or polygonal cell bodies, the largest diameter of the soma was determined. The data reflecting the diameter of the individual types of neurones were pooled, the results are expressed as mean \pm S.D.

\section{Results}

\subsection{Purkinje-like cells}

Recognition of the PLCs could be easily achieved on the basis of their strong calbindin positivity [38]. The spherical or slightly elongated somata of the PLCs (diameter: $32 \pm 4 \mu \mathrm{m}$ $[n=8]$ ) always appeared in the most superficial layer of the DCN (Fig. 2A, arrows). The rich and highly asymmetric dendritic arborisations always ran towards the centre of the nucleus, often obscuring the cell body. An example of this situation is illustrated in Fig. 2C, showing two PLCs with partially overlapping dendritic trees. As demonstrated, the cell bodies could only be seen after a $180^{\circ}$ horizontal rotation of the image (Fig. 2D, arrows), indicating that visualisation of the PLC bodies may be difficult in certain cases. The number of visible processes of the PLCs was highly variable, ranging between 1 and 8 .
Rhodamine filling of the PLCs was performed from lesions performed at the cerebellar peduncles, resulting in a characteristic patchy labelling pattern in the superficial layer of the DCN (Fig. 2B, main image). These labelled structures not only appeared in that part of the CN where PLCs are found, but they clearly resembled the distribution of the calbindinspecific immunoreactions. Similar labelling pattern could never be observed after performing midline incisions (Fig. 1A), which, however, effectively filled projection neurones of the deeper layers in the DCN (Fig. 2B, inset).

The main panel of Fig. 2E demonstrates the composite image of a rhodamine-labelled PLC (arrow indicates the most likely position of the cell body), whose appearance resembles that of a calbindin-labelled single PLC (Fig. 2E, inset).

\subsection{Bushy cells}

Bushy cells usually appeared in a columnar fashion amongst the intranuclear fibres of the acoustic nerve in the $\mathrm{VCN}$ (not shown). The acoustic nerve fibres also showed labelling in some cases (Fig. 3A and B), suggesting that diffusion of rhodamine could occur in the moisture covering the surface of the brain stem, eventually reaching the cut ends of the acoustic nerve fibres and causing their orthograde labelling.

Please cite this article in press as: K. Pocsai et al., Rhodamine backfilling and confocal microscopy as a tool for the unambiguous identification of neuronal cell types: A study of the neurones of the rat cochlear nucleus, Brain Res. Bull. (2006), doi:10.1016/j.brainresbull.2006.11.009 

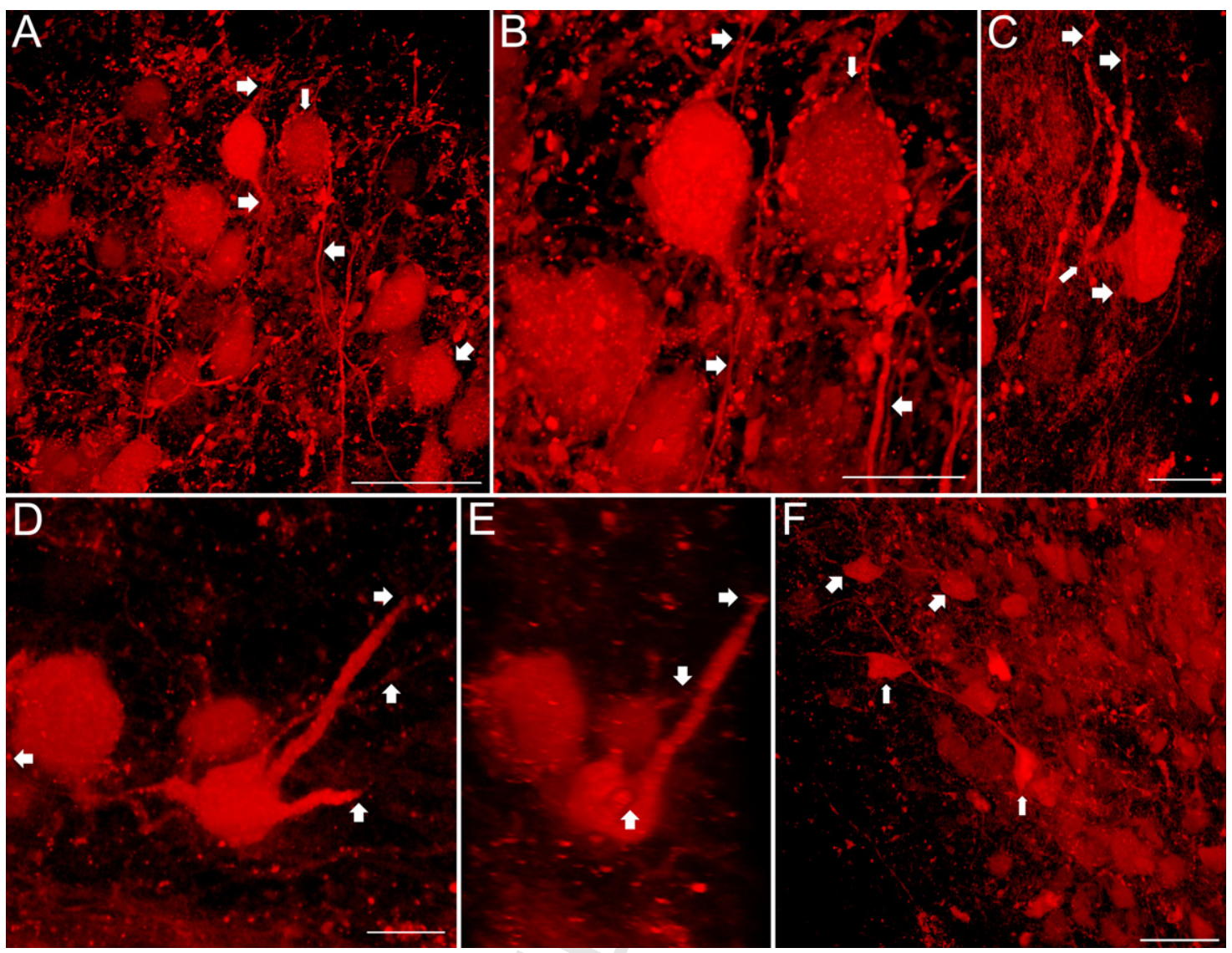

Fig. 3. Retrograde labelling of bushy and octopus neurones. (A) Rhodamine-filled bushy cells. Thick arrows pointing to the right indicate two processes originating from the opposite poles of the cell body. Thin arrow indicates end-terminals of the acoustic nerve. Thick arrow pointing to the left indicates an acoustic fibre; oblique arrow shows another bushy cell. (B) Higher magnification view of the two prominent bushy cells demonstrated in (A). (C) A typical octopus cell. Thick arrows indicate the processes; thin arrow marks a point where one of the processes makes a more than $90^{\circ}$ turn. (D and E) Reconstructed images of an octopus cell from different views. (F) A reconstructed image of a slice showing octopus (thick arrows) and giant cells (thin arrows) in close vicinity. Calibrations: $50 \mu \mathrm{m}$ (A and F); $20 \mu \mathrm{m}$ (B-E).

Composite confocal images showed the characteristic shape and distribution of the bushy cells (Fig. 3A and B). The neurones possessed globular or slightly elongated cell bodies (diameter: $22 \pm 3 \mu \mathrm{m}$, ranging between 18 and $25 \mu \mathrm{m} ; n=22$ ), possessing two processes emerging from roughly the opposite poles of the somata (horizontal arrows pointing to the right and oblique arrow), and proceeding away from each other. The cell indicated by a thin arrow was also clearly labelled, and its soma was covered by bright structures showing granular appearances. The localisation of these structures along with the fact that some of them were in contact with the acoustic nerve fibres (thick arrow pointing to the left in Fig. 3A and B) suggested that these were nerve terminals forming axo-somatic synaptic contacts with the bushy cells. All neurones identified as bushy cells in the present study had two processes with a single exception, where only a single one was noted (Table 1). It is most likely that in this cell one of the processes had been truncated during the preparation of the slice, as the projection, localisation and visible characteristics of this cell clearly defined it as a bushy neurone.

\subsection{Octopus cells}

As Fig. 3C-F illustrate, octopus neurones may have rather variable appearances, depending on the plane of the investiga- tion. Nevertheless, they always had slightly elongated somata, with an average diameter of $26 \pm 4 \mu \mathrm{m}$ (ranging between 18 and $32 \mu \mathrm{m} ; n=20$ ). Fig. $3 \mathrm{C}$ shows a typical octopus neurone with an elongated cell body as well as several processes emerging from the same side of the soma, and running into the same direction (arrows); one of them producing an extremely sharp turn (thin arrow).

Fig. 3D and E present the composite image of an octopus cell from different angles. Fig. 3D shows the image when the cell was observed vertically (directly looking into the slice). As seen, all visible processes of the neurone (arrows) travel into the same direction. In order to get Fig. 3E, the image was rotated $60^{\circ}$ clockwise (vertically), providing some depth perception. From this aspect, the process pointing to the right in Fig. 3D is now running directly out of the plane of the paper. The rather thick and prominent initial parts of the major processes are also shown, and it is revealed that two processes which seemed to be directly adjacent in Fig. 3D, are in fact behind each other at a considerable distance.

Most of the octopus neurones investigated in the present work possessed three distinguishable processes, whereas others had two, four or five appendages (Table 1). Generally, it seems to be possible that octopus cells presenting two processes may be confused with bushy neurones, especially as there is a consid-

Please cite this article in press as: K. Pocsai et al., Rhodamine backfilling and confocal microscopy as a tool for the unambiguous identification of neuronal cell types: A study of the neurones of the rat cochlear nucleus, Brain Res. Bull. (2006), doi:10.1016/j.brainresbull.2006.11.009 
Table 1

Diameter of the cell bodies and number of distinguishable processes of the various projection neurones of the rat $\mathrm{CN}$

\begin{tabular}{|c|c|c|c|c|c|c|c|c|c|}
\hline \multirow[t]{2}{*}{ Cell type } & \multirow[t]{2}{*}{$n$} & \multicolumn{4}{|c|}{ Largest diameter of the soma $(\mu \mathrm{m})$} & \multicolumn{4}{|c|}{ Number of distinguishable processes } \\
\hline & & Mean \pm S.D. & Minimum & Maximum & Reference & 2 & 3 & 4 & 5 \\
\hline PLC & 8 & $22 \pm 4$ & 16 & 28 & $25[20]$ & \multicolumn{4}{|c|}{$1-8^{\mathrm{a}}$} \\
\hline Bushy & 22 & $22 \pm 3$ & 18 & 25 & $20-28[25]$ & $21(95 \%)^{\mathrm{b}}$ & - & - & - \\
\hline Octopus & 20 & $26 \pm 4$ & 18 & 32 & $30-35[25]$ & $4(20 \%)$ & $10(50 \%)$ & $4(20 \%)$ & $2(10 \%)$ \\
\hline Giant (all) & 31 & $37 \pm 9$ & 27 & 64 & $40-50[25]$ & - & $15(48 \%)$ & $11(35 \%)$ & $5(16 \%)$ \\
\hline Giant (3 processes & 15 & $34 \pm 7$ & 27 & 53 & & & & & \\
\hline Pyramidal & 16 & $23 \pm 3$ & 18 & 27 & $15-25[12]$ & - & $16(100 \%)$ & - & - \\
\hline
\end{tabular}

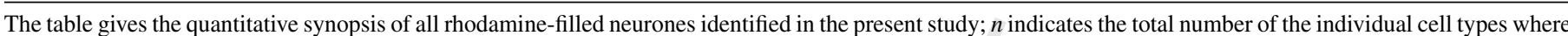

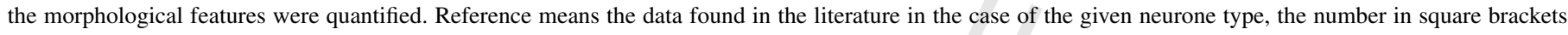

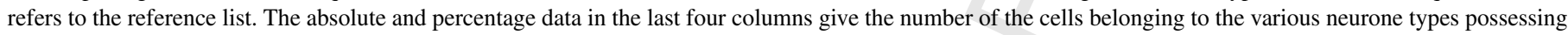
the appropriate amount of processes.

a PLCs had highly variable number of distinguishable appendages; but due to the rare occurrence of this cell type, further classification seemed unnecessary.

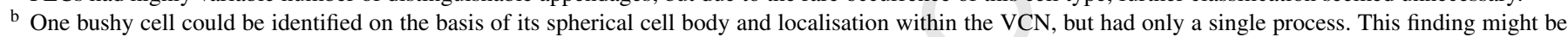
due to poor filling or to losing the other appendage during the manipulation of the slice.

erable overlap between the diameters of these neurones. There are, however, two features which may help in distinguishing between these cell types. First, the processes of the octopus cells tend to run towards the same direction, whereas in the cases of the bushy neurones they usually proceed away from each other. Second, octopus cells are strictly restricted to the pVCN region; thus octopus cells and bushy cells are likely to be far away from each other unlike, for example, the giant cells which may be in the close proximity of octopus neurones (Fig. 3F).

\subsection{Giant and pyramidal cells}

Giant cells have large (Figs. 3F and 4A-E), relatively flat, polygonal cell bodies and at least 3 processes (Table 1, [28]). The average diameter of the giant cells was $37 \pm 9 \mu \mathrm{m}(n=31)$, ranging from 27 to $64 \mu \mathrm{m}$; thus giant cells having greater than $60 \mu \mathrm{m}$ diameter are not uncommon. Although the size of the giant cells is usually enough for their unambiguous identification, there are some situations when the precise classification is not easy. One of these examples is demonstrated in Fig. 4E, where a cell, exhibiting an elongated, distinctly fusiform shape is seen. Only when this image was rotated $54^{\circ}$ clockwise, was the usual appearance of the cell revealed (Fig. 4D), demonstrating the characteristic polygonal cell body and several processes. This finding pointed out that - although giant cells always possessed polygonal (or sometimes triangular) cell body with at least three processes - in certain planes these morphological features may not be obvious. In these instances the size of the cell body and the bifurcation of one of the processes situated near the soma may be rather informative.

Similarly to the giant cells, pyramidal (or fusiform) neurones also project via the dorsal acoustic stria, consequently, their labelling was achieved by the same technique as used for giant neurones. Considering the fact that pyramidal cells possess triangular cell body (Fig. 4F) from which three processes emerge (Table 1), it is not surprising that giant and pyramidal cells may have very similar appearances, especially if the giant neurone has three processes (as approximately half of the giant cells had in this study; Table 1). If this is the case, their location may help in their identification (pyramidal cells are situated in the second layer of the DCN, whereas giant cells are found in both the $\mathrm{VCN}$ and the deep part of the DCN). The diameter of the cell body is the other obvious clue helping the classification: pyramidal cells were found to be $23 \pm 3 \mu \mathrm{m}$ in diameter $(n=16)$, whereas giant cells possessing three processes are generally larger, $34 \pm 7 \mu \mathrm{m}$ $(n=15)$. Even more importantly, the diameters of the pyramidal and 3-processed giant neurones ranged between 18-27 and $27-53 \mu \mathrm{m}$, respectively; indicating that a triangular cell with less than $25 \mu \mathrm{m}$ soma diameter most likely belongs to the pyramidal cell population, whereas larger cells can be safely classified as giant neurones.

One of the possible reasons of misidentification is presented in Fig. 4G showing the optical section of a giant cell performed $7.15 \mu \mathrm{m}$ from the top of the neurone. Comparison of Fig. 4G with Fig. 4F not only reveals that the shape of the giant neurone is the same as that of a pyramidal cell, but in this section even the size of the soma is in the appropriate range, thus unambiguous classification of the triangular cells cannot be achieved without finding the largest diameter of the cell body. This observation is exemplified in Fig. $4 \mathrm{H}$, demonstrating the composite image of the same cell (rotated $41^{\circ}$ forward relative to Fig. $4 \mathrm{G}$ ), where the true morphology of the neurone can be assessed including the full size of the soma and the bifurcation of one of the processes situated in the close proximity of the cell body (thin arrow).

Interestingly, the appearances of giant cells may easily mimic the morphological features of other (non-pyramidal) cell types. Fig. 4I and J demonstrate single optical sections of the same cell. Fig. 4I illustrates the elongated cell body, and the very beginning of the processes originating from the same side of the cell. The section produced $8.4 \mu \mathrm{m}$ below the previous one (Fig. 4J) gives similar impression and indicates two non-branching processes emerging from the same side of the soma. Thus, one may be tempted to believe that these images belong to an octopus cell. However, when the composite image was constructed and slightly rotated counter clockwise $\left(19^{\circ}\right.$; Fig. 4K), the cell clearly exhibited polygonal shape, with several processes 

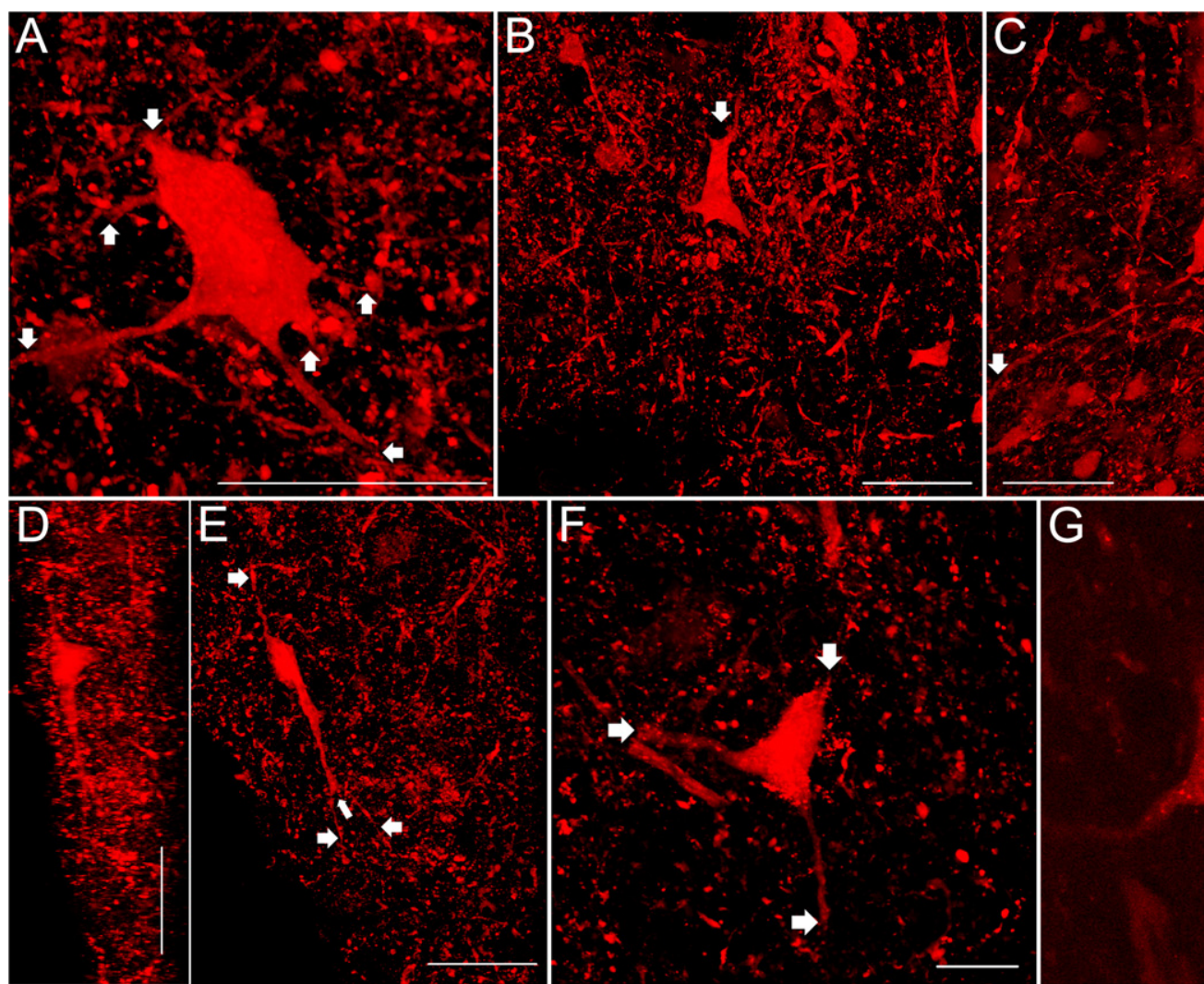

$H$

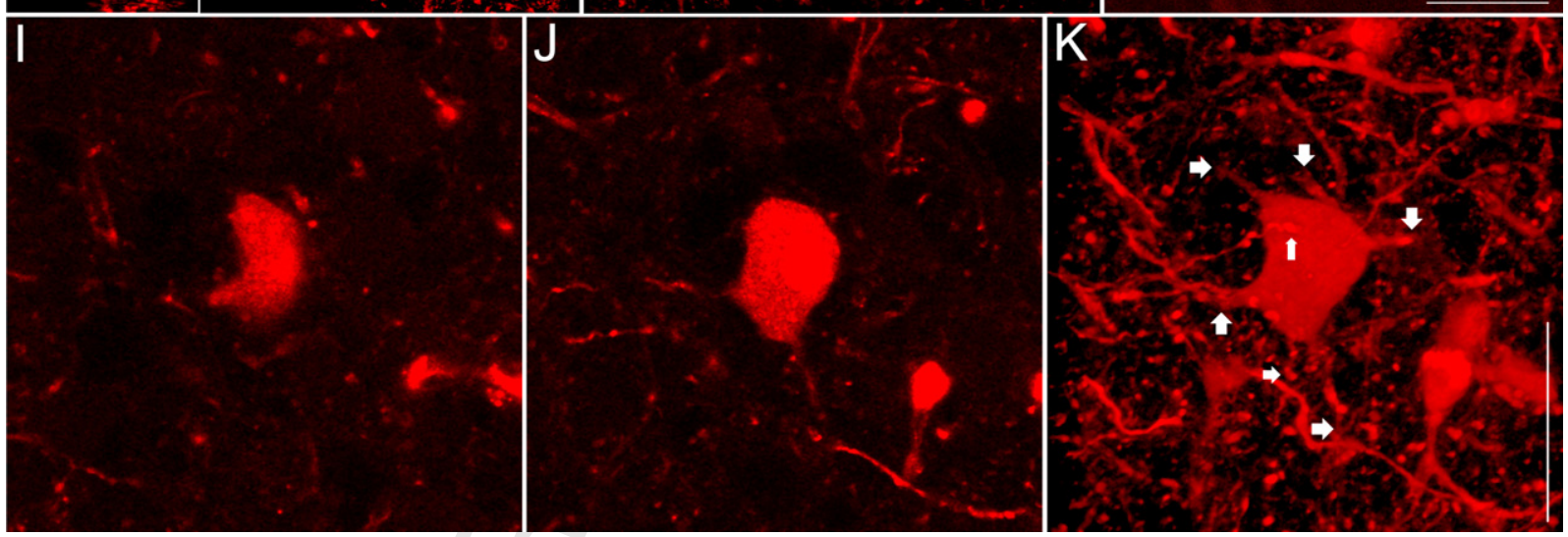

Fig. 4. Morphological appearances and similarities of giant and pyramidal cells. (A-D) Reconstructed images of giant cells. Thick arrows indicate the farthest points where the processes are still visible (A and C), thin arrow shows a branching point (C). (E) Same cell as in (D), but the image was rotated $54^{\circ}$ counterclockwise. Thick arrows indicate the processes, thin arrow points to a bifurcation point. (F) Composite view of a typical pyramidal cell, arrows indicate the processes. (G) Single optical section of a giant cell resembling the morphology of pyramidal neurones. (H) Reconstructed image of the same cell (after a $41^{\circ}$ rotation forward); thick arrows indicate two processes, thin arrow shows the bifurcation of the third process. The diameter of the cell is $36 \mu \mathrm{m}$. (I and J) Single optical sections of a giant cell, resembling an octopus neurone. (K) Composite image of the same cell as in (I and J), rotated $19^{\circ}$ counter clockwise, arrows indicate the emerging processes. Calibrations: $20 \mu \mathrm{m}(\mathrm{F}) ; 50 \mu \mathrm{m}$ (in every other case).

(arrows) emerging from different parts of the cell and running into various directions, classifying it as a giant neurone.

\section{Discussion}

In this work, rhodamine backfilling and subsequent confocal analysis was employed to seek morphological features which may facilitate correct cell identification of the principal projection neurones of the rat $\mathrm{CN}$. Confocal analysis of the individual cells not only gave the possibility to reconstruct the three-dimensional appearances of the neurones, providing, therefore, a better understanding of the arrangement and relative positions of their somata and processes within the nucleus, but it also allowed the investigation of the images of the cells from planes which are usually not preferred when performing morphological studies. This manipulation emphasised the plausible hypothesis that in many cases the plane selected for slicing may so substantially alter the morphological characteristics of the cells that it may eventually lead to false cell identification. Beside the methodological results of the present work, it was also shown that PLCs of the CN project to the cerebellum.

Please cite this article in press as: K. Pocsai et al., Rhodamine backfilling and confocal microscopy as a tool for the unambiguous identification of neuronal cell types: A study of the neurones of the rat cochlear nucleus, Brain Res. Bull. (2006), doi:10.1016/j.brainresbull.2006.11.009 


\subsection{Morphological identification of CN neurones after filling with fluorescent dyes}

The advent of microelectrode techniques and the application of specific tracer molecules in the pipette solution allowed the anterograde and retrograde filling of neurones, thus these studies not only provided valuable information about the functional properties of the cells investigated, but largely contributed to our understanding of their morphological features. Markers regularly applied for such purposes include horseradish-peroxidase [1-4,8,14,26,27,29,36,40,47], biocytin [48,49], neurobiotin [8,17,37], Lucifer Yellow [24] and Phaseolus vulgaris leucoagglutinin [32]. Obviously, intracellular filling was particularly successful in establishing morphology/function correlations when it was combined with electrophysiological recordings.

The rhodamine backfilling method had already been successfully applied for labelling some neuronal structures [9,31,41], and in the present work the applicability of this marker and method has been demonstrated in the $\mathrm{CN}$ as well. This technique offers some clear advantages: application of the crystals into well-targeted lesions prevents the longdistance diffusion of the tracer molecules and, consequently, the unintentional filling of large and diverse neurone populations. Moreover, rhodamine-filled neurones may also be applicable for subsequent immunolabelling. The advantage of performing immunostaining on a considerable number of identified neurones is plausible if one considers the difficulties of distinguishing between cell types in experiments where certain membrane proteins are labelled only $[19,46]$. Moreover, rhodamine-filled neurones can be studied with confocal microscopy, and this technique can obviously provide new pieces of valuable information about the three-dimensional arrangement of the $\mathrm{CN}$ complex.

It must also be noted, however, that despite its generally good applicability, rhodamine backfilling has certain disadvantages. Most importantly, combination of the retrograde rhodamine-labelling with the application of immunohistochemistry targeting cytoplasmic components $[31,41]$ was not always possible [30]. It was also established that, similarly to other intracellular tracers, the labelling of the processes is usually partial only, which may be the consequence of either the relatively long in vitro survival or the fixation method.

\subsection{Morphological diversity of the CN neurones}

The present paper provides evidence that misidentification of certain neurones of the $\mathrm{CN}$, even if they possess unique morphological features, is possible. Careful morphological studies conducted earlier provided the fundamental knowledge for the identification of the cells and led to the widely accepted view that both the structure of this nucleus and the features of the individual neurones show close resemblance in cat $[5,21,22,36,37]$, rat $[3,6,11,14,23,45,44]$, guinea pig [16,24], mouse [15,26,27,42,47-49], gerbil [8,17,29], hamster [35,34], chinchilla [29], rabbit [10] and primates, including humans [18]. Despite the similarities, however, cell recognition is often complicated by some interspecies differences. During the phy- logenesis of the DCN, for example, the pyramidal cells seem to preserve their distribution in the outer layers, while the number of giant cells in the deeper parts is more variable [23]. Moreover, the deepest layer of the DCN was found to be poorly developed in rats, indicating that giant cells may be less frequent in this region than in other species.

In the light of the data presented in this work, it is possible that giant and pyramidal neurones might have been confused with each other. This possibility is further substantiated by the fact that these two cell types seem to have almost negligible physiological differences in cats [37]; consequently, even the simultaneous functional measurements cannot completely exclude false identification.

Although the number of the octopus cells is rather limited in the CN (approximately 200 octopus neurones may be present in mice; [15]), their restricted localisation in the pVCN and the characteristic arrangement of their dendrites [27] suggest an easy identification. Despite this, morphological and physiological similarities between the octopus and globular bushy cells have been noted [37], raising the possibility of potential bushy-octopus misidentifications, too.

Precise cell identification in the $\mathrm{CN}$ is further complicated by known developmental modifications. In hamster, a similarity of pyramidal and giant cells in newborn individuals was described [35], and the possible confusion is further aggravated by the fact that pyramidal neurones may frequently develop a third dendrite in this species [34]. Aging of mice modifies the shape of the dendritic branches of the octopus cells [43], and some developmental changes of the various neurones in primates have been noted, too [18]. Although there are no data specific for rats, it cannot be excluded that similar modifications might contribute to the morphological diversity of the various neurones in this species as well.

\subsection{Purkinje-like cells of the $C N$}

As their name suggests, PLCs are considered as ectopic Purkinje cells that might migrate to the $\mathrm{CN}$ during embryogenesis [20,32,38]. Initially, they had been overlooked in classical morphological studies; but later on their presence was consistently described in mice, rats and guinea pigs. Although the exact roles and significance of the PLCs in the cochlear neural circuits are still debated, there is a consensus regarding their similarity to cerebellar Purkinje cells, including their strong calbindin and less pronounced parvalbumin expressions in rats $[13,38]$. The relationship between the two cell populations is further emphasised by the fact that PLCs receive climbing fibres from the inferior olivary area of the rat [32]. Furthermore, there are data indicating that the axons of the PLCs may reach cerebellar nuclei [38]. In the present study, PLCs could be labelled by applying rhodamine to incisions of the cerebellar peduncles, supporting the possible cerebellar projection of these cells.

\section{Acknowledgements}

This work was supported by grants from the Hungarian Science Foundation (OTKA T-046067) and from The 
Wellcome Trust (Collaborative Research Initiative Grant No. 075243/Z/04/Z). The authors are indebted to Dr. Beatrix Dienes for her help on confocal microscopy, to Áron Kőszeghy for participating in some of the experiments and to Mrs. Ibolya Varga for her skilled technical assistance.

\section{References}

[1] L. Alibardi, Ultrastructural and immunocytochemical characterization of neurons in the rat ventral cochlear nucleus projecting to the inferior colliculus, Ann. Anat. 180 (1998) 415-426.

[2] L. Alibardi, Fine structure, synaptology and immunocytochemistry of large neurons in the rat dorsal cochlear nucleus connected to the inferior colliculus, J. Hirnforsch. 39 (1999) 429-439.

[3] L. Alibardi, Ultrastructure and immunocytochemical characteristics of cells in the octopus cell area of the rat cochlear nucleus: comparison with multipolar cells, Ann. Anat. 185 (2003) 21-33.

[4] B.D. Beyerl, Afferent projections to the central nucleus of the inferior colliculus in the rat, Brain Res. 145 (1978) 209-223.

[5] T.W. Blackstad, K.K. Osen, E. Mugnaini, Pyramidal neurones of the dorsal cochlear nucleus: a Golgi and computer reconstruction study in cat, Neuroscience 13 (1984) 827-854.

[6] J.R. Brawer, D.K. Morest, E.C. Kane, The neuronal architecture of the cochlear nucleus of the cat, J. Comp. Neurol. 155 (1974) 251-300.

[7] N.B. Cant, C.G. Benson, Parallel auditory pathways: projection patterns of the different neuronal populations in the dorsal and ventral cochlear nuclei, Brain Res. Bull. 60 (2003) 457-474.

[8] J. Ding, T.E. Benson, H.F. Voigt, Acoustic and current-pulse responses of identified neurons in the dorsal cochlear nucleus of unanesthetized, decerebrate gerbils, J. Neurophysiol. 82 (1999) 3434-3457.

[9] Q.T. Dinh, A. Cryer, S. Dinh, M. Trevisani, P. Georgiewa, F. Chung, P. Geppetti, W. Heppt, B.F. Klapp, A. Fischer, Protease-activated receptor 2 expression in trigeminal neurons innervating the rat nasal mucosa, Neuropeptides 39 (2005) 461-466.

[10] J.F. Disterhoft, R.E. Perkins, S. Evans, Neuronal morphology of the rabbit cochlear nucleus, J. Comp. Neurol. 192 (1980) 687-702.

[11] J.R. Doucet, D.K. Ryugo, Projections from the ventral cochlear nucleus to the dorsal cochlear nucleus in rats, J. Comp. Neurol. 385 (1997) 245-264.

[12] M.G. Fiori, E. Mugnaini, Subsurface and cytoplasmic cisterns associated with mitochondria in pyramidal neurons of the rat dorsal cochlear nucleus, Neuroscience 6 (1981) 461-467.

[13] E. Friauf, Distribution of calcium-binding protein calbindin-D28k in the auditory system of adult and developing rats, J. Comp. Neurol. 349 (1994) 193-211.

[14] E. Friauf, J. Ostwald, Divergent projections of physiologically characterized rat ventral cochlear nucleus neurons as shown by intra-axonal injection of horseradish peroxidase, Exp. Brain Res. 73 (1988) 263-284.

[15] N.L. Golding, D. Robertson, D. Oertel, Recordings from slices indicate that octopus cells of the cochlear nucleus detect coincident firing of auditory nerve fibers with temporal precision, J. Neurosci. 15 (1995) 3138-3153.

[16] C.M. Hackney, K.K. Osen, J. Kolston, Anatomy of the cochlear nuclear complex of guinea pig, Anat. Embryol. (Berl) 182 (1990) 123-149.

[17] K.E. Hancock, H.F. Voigt, Intracellularly labeled fusiform cells in dorsal cochlear nucleus of the gerbil. II. Comparison of physiology and anatomy, J. Neurophysiol. 87 (2002) 2520-2530.

[18] T.D. Heiman-Patterson, N.L. Strominger, Morphological changes in the cochlear nuclear complex in primate phylogeny and development, J. Morphol. 186 (1985) 289-306.

[19] C. Hunter, R.S. Petralia, T. Vu, R.J. Wenthold, Expression of AMPAselective glutamate receptor subunits in morphologically defined neurons of the mammalian cochlear nucleus, J. Neurosci. 13 (1993) 1932-1946

[20] L.B. Hurd, M.L. Feldman, Purkinje-like cells in rat cochlear nucleus, Hear. Res. 72 (1994) 143-158.

[21] E.C. Kane, Synaptic organisation in the dorsal cochlear nucleus of the cat: a light and electron microscopic study, J. Comp. Neurol. 155 (1974) 301-330.
[22] E.S. Kane, S.G. Puglisi, B.S. Gordon, Neuronal types in the deep dorsal cochlear nucleus of the cat. I. Giant neurons, J. Comp. Neurol. 198 (1981) 483-513.

[23] M.S. Malmierca, The structure and physiology of the rat auditory system: an overview, Int. Rev. Neurobiol. 56 (2003) 147-211.

[24] P.B. Manis, Membrane properties and discharge characteristics of guinea pig dorsal cochlear nucleus neurons studied in vitro, J. Neurosci. 10 (1990) 2338-2351.

[25] J.K. Moore, Cochlear nuclei: relationship to the auditory nerve, in: R.A. Altschuler, D.W. Hoffman, R.P. Bobbin (Eds.), Neurobiology of Hearing: The Cochlea, Raven Press, New York, 1986, pp. 283-301.

[26] D. Oertel, S.H. Wu, Morphology and physiology of cells in slice preparations of the dorsal cochlear nucleus of mice, J. Comp. Neurol. 283 (1989) 228-247.

[27] D. Oertel, S.H. Wu, M.W. Garb, C. Dizack, Morphology and physiology of cells in slice preparations of the posteroventral cochlear nucleus of mice, J. Comp. Neurol. 295 (1990) 136-154.

[28] K.K. Osen, Cytoarchitecture of the cochlear nuclei in the cat, J. Comp. Neurol. 136 (1969) 453-484.

[29] E.M. Ostapoff, J.J. Feng, D.K. Morest, A physiological and structural study of neuron types in the cochlear nucleus. II. Neuron types and their structural correlation with response properties, J. Comp. Neurol. 346 (1994) 19-42.

[30] Á. Pór, K. Pocsai, Z. Rusznák, G. Szûcs, Presence and distribution of three calcium binding proteins in projection neurons of the adult rat cochlear nucleus, Brain Res. 1039 (2005) 63-74.

[31] R.J. Richardson, I. Grkovic, A.M. Allen, C.R. Anderson, Separate neurochemical classes of sympathetic postganglionic neurons project to the left ventricle of the rat heart, Cell Tissue Res. 324 (2006) 9-16.

[32] F. Rossi, T. Borsello, Ectopic Purkinje cells in the adult rat: olivary innervation and different capabilities of migration and development after grafting, J. Comp. Neurol. 337 (1993) 70-82.

[33] D.K. Ryugo, F.H. Willard, The dorsal cochlear nucleus of the mouse: a light microscopic analysis of neurons that project to the inferior colliculus, J. Comp. Neurol. 242 (1985) 381-396.

[34] L. Schweitzer, Differentiation of apical, basal and mixed dendrites of fusiform cells in the cochlear nucleus, Brain Res. Dev. Brain Res. 56 (1990) 19-27.

[35] L. Schweitzer, N.B. Cant, Differentiation of the giant and fusiform cells in the dorsal cochlear nucleus of the hamster, Brain Res. 352 (1985) 6982

[36] S. Sento, D.K. Ryugo, Endbulbs of held and spherical bushy cells in cats: morphological correlates with physiological properties, J. Comp. Neurol. 280 (1989) 553-562.

[37] P.H. Smith, A. Massie, P.X. Joris, Acoustic stria: anatomy of physiologically characterized cells and their axonal projection patterns, J. Comp. Neurol. 482 (2005) 349-371.

[38] W.B. Spatz, Differences between guinea pig and rat in the dorsal cochlear nucleus: expression of calcium-binding proteins by cartwheel and Purkinjelike cells, Hear. Res. 107 (1997) 136-146.

[39] G. Szûcs, Z. Rusznák, Cellular regulatory mechanisms influencing the activity of the cochlear nucleus: a review, Acta Physiol. Hung. 89 (2002) $375-414$.

[40] L.P. Tolbert, D.K. Morest, D.A. Yurgelun-Todd, The neuronal architecture of the anteroventral cochlear nucleus of the cat in the region of the cochlear nerve root: horseradish peroxidase labelling of identified cell types, Neuroscience 7 (1982) 3031-3052.

[41] J.N. Tolosa, R. Cooper, A.C. Myers, G.L. McLemore, F. Northington, E.B. Gauda, Ontogeny of retrograde labeled chemoafferent neurons in the newborn rat nodose-petrosal ganglion complex: an ex vivo preparation, Neurosci. Lett. 384 (2005) 48-53.

[42] D.B. Webster, D.R. Trune, Cochlear nuclear complex of mice, Am. J. Anat. 163 (1982) 103-130.

[43] J.F. Willott, L.S. Bross, Morphology of the octopus cell area of the cochlear nucleus in young and aging C57BL/6J and CBA/J mice, J. Comp. Neurol. 300 (1990) 61-81.

[44] F.G. Wouterlood, E. Mugnaini, Cartwheel neurons of the dorsal cochlear nucleus: a Golgi-electron microscopic study in rat, J. Comp. Neurol. 227 (1984) 136-157. 
[45] F.G. Wouterlood, E. Mugnaini, K.K. Osen, A.-L. Dahl, Stellate neurons in rat dorsal cochlear nucleus studied with combined Golgi impregnation and electron microscopy: synaptic connections and mutual coupling by gap junctions, J. Neurocytol. 131 (1984) 639-664.

[46] D.D. Wright, C.D. Blackstone, R.L. Huganir, D.K. Ryugo, Immunocytochemical localization of the mGluR1 alpha metabotropic glutamate receptor in the dorsal cochlear nucleus, J. Comp. Neurol. 364 (1996) 729-745.
[47] S.H. Wu, D. Oertel, Intracellular injection with horseradish peroxidase of physiologically characterized stellate and bushy cells in slices of mouse anteroventral cochlear nucleus, J. Neurosci. 4 (1984) 1577-1588.

[48] S. Zhang, D. Oertel, Giant cells of the dorsal cochlear nucleus of mice: intracellular recordings in slices, J. Neurophysiol. 69 (1993) 1398-1408.

[49] S. Zhang, D. Oertel, Neuronal circuits associated with the output of the dorsal cochlear nucleus through fusiform cells, J. Neurophysiol. 71 (1994) 914-930.

Please cite this article in press as: K. Pocsai et al., Rhodamine backfilling and confocal microscopy as a tool for the unambiguous identification of neuronal cell types: A study of the neurones of the rat cochlear nucleus, Brain Res. Bull. (2006), doi:10.1016/j.brainresbull.2006.11.009 